\title{
The shifting roles of museums
}

\author{
Museums have become an important venue for scientists and the public to have conversations about \\ nanotechnology, reports Ai Lin Chun.
}

W hen we hear the word museum (which originates from Latin and describes a place for learning), we often imagine a large building containing collections of artefacts; a place where we go to admire what curators have set in front of us. But as societies and our expectations evolve, many science museums around the world (http://blogs.nature. com/ofschemesandmemes/2011/02/21/ mapping-the-worlds-science-museums) are being transformed - there are now more places where we can play with exhibits, ask questions and look to be inspired by cutting-edge and socially relevant topics, such as nanotechnology.

"From being about something to being for somebody," the late Stephen E. Weil of the Smithsonian Institution's Center for Education and Museum Studies wrote in 1999 as he described how the transformation of museums in the United States should be viewed as instruments for social change with a sense of purpose centred on education and visitors (Daedalus 128, 229-258; 1999). More than a decade later, this reflection has become a reality. "Museology, which is the science and practice of organizing, arranging and managing museums, has changed emphasis from collections to audiences and from objects to stories. [Also,] informal learning methodologies adopted in museum exhibitions and programmes put the learner at the centre of experience," says Fiorenzo Galli, Director General of the Museo Nazionale della Scienza e Technologia Leonardo da Vinci in Milan, which is one of several museums participating in Project NanoToTouch (www.nanototouch.eu/project).

Project NanoToTouch, which is funded by the European Union Seventh Framework Program under the Science in Society initiative, aims to allow the public to experience how research in nanotechnology is carried out and to encourage dialogue between the public and researchers. One way this is accomplished is through the Open Nano Lab - a fully equipped nanoscience research lab that is situated within the museum and has glass walls that allow visitors to observe and interact with the researchers. The Nano Lab, which was first launched in Deutsches Museum in Munich in 2006, has also been implemented in Gothenburg.
It is an opportunity to "bring academic research into the museum setting," says Galli. Alongside this, the museum cooperates with the researchers to organize education programmes on nanotechnology for schools and families, training courses for teachers and special events for adult visitors.

The lab is a new and interesting experience for visitors and researchers alike. "[Initially], you are easily distracted and embarrassed by the presence of the visitors [because] working in a public space means [being] under the [watchful] eye of a lot of people," says Luca Bettini, a postdoctoral researcher at the Interdisciplinary Centre for Nanostructured Materials and Interfaces of the University of Milan, who does his experiments at the lab in Milan and spends time chatting with visitors. "However, [once] you find the right balance between research and communication activities, you understand the uniqueness of this experience," he adds.

The dialogue with visitors is mainly driven by their curiosity. In general, visitors are first quizzed about their knowledge on nanotechnology and the researchers then explain the fundamental concepts (such as length scale), the potential benefits to various sectors, why the field is attracting huge investments and, importantly, why there is a need for dialogue between the public and the scientists. Most visitors are interested in learning about the safety of nanotechnology-based consumer products and in understanding how to draw the line between fiction and reality. Bettini admits that he is frequently surprised by questions that arise from the catastrophic portrayal of nanotechnology in science fiction books and movies. Such negative perceptions of nanotechnology mean that there is a lot of educating to do and open conversations to be had.

Across the Atlantic, a similar trend has taken shape. With funds from the National Science Foundation, museums, researchers and informal science educators in the United States have together formed a network called Nanoscale Informal Science Education (NISE), which aims to foster "public awareness, engagement, and understanding of nanoscale science, engineering, and technology" (www.nisenet.org). The network, which is organized around seven regional hubs with hub leaders helping museum educators connect with scientists, has created a wide range of materials for educators and scientists. These vary from mini exhibitions, a nano game app and hands-on activities to programming ideas for science cafes, NanoDays (a nationwide festival of education programmes about nanoscience), and theatre and stage presentations. Furthermore, NISE has developed a guide to teach those involved (be it museum professionals or researchers) to have 'museum conversations' that help visitors think about nanotechnology more personally, and empower them to help shape the future of nanoscience.

Elsewhere in Singapore, things look slightly different. Back in the 1970s when the country was rapidly modernizing, the government of Singapore created the Science Centre Singapore (which was born from the National Museum of Singapore) to be the "custodian of creativity and innovation", so that the museum could focus on safekeeping collections of art and history (www.science.edu.sg/Pages/ SCBHome.aspx). "[Our] mission is to promote interest, learning and creativity through an imaginative and enjoyable experience, and to contribute to [the development of our] nation's human resources," explains Daniel Tan, Acting Senior Director of Projects and Exhibitions of the Science Centre Singapore. "Therefore, our nation's needs guide [our work and choice of topics to feature]," adds Tan. The Science Centre featured nanotechnology in 2010 because the Singapore government had invested heavily in nanotechnology research and, being a buzzword in the news, it became timely for the public to understand why nanotechnology is important.

The shift in focus away from caring for and studying collections to the audience has also changed the way museums are staffed and managed. Although museums still have inhouse experts in informal education, exhibit designers and engineers, and specialists for specific exhibits, they are also increasingly collaborating with research institutions, researchers and industry. For anyone interested in science communication beyond the bench and the classroom, museums might be the place to be.

AI LIN CHUN is a Senior Editor at Nature Nanotechnology.e-mail: a.chun@nature.com 